American Journal of Pharmacology and Toxicology 5 (4): 159-166, 2010

ISSN 1557-4962

(C) 2010 Science Publications

\title{
Toxicity Evaluation of Yoyo 'Cleanser' Bitters and Fields Swedish Bitters Herbal Preparations following Sub-Chronic Administration in Rats
}

\author{
${ }^{1,2}$ Martins Ekor, ${ }^{2,3}$ Odusoga Adewale Osonuga, ${ }^{4}$ Adesina Olalekan Odewabi, \\ ${ }^{2,5}$ Adewale Ganiyu Bakre and ${ }^{6}$ Kolawole Sunday Oritogun \\ ${ }^{1}$ Department of Chemical Sciences, Redeemer's University, Nigeria \\ ${ }^{2}$ Department of Pharmacology, Olabisi Onabanjo University, Nigeria \\ ${ }^{3}$ Department of Pharmacology, Faculty of Medical Sciences, University of Cape Coast, Ghana \\ ${ }^{4}$ Department of Chemical Pathology, Olabisi Onabanjo University Teaching Hospital, Nigeria \\ ${ }^{5}$ Department of Pharmacology, Niger Delta University, Nigeria \\ ${ }^{6}$ Biostatistics unit, Department of Medical Microbiology \& Parasitology, \\ Olabisi Onabanjo University, Nigeria
}

\begin{abstract}
Problem statement: Owing to numerous adverse effects of most orthodox pharmaceuticals, the use of herbal remedies in treatment and prevention of diseases is gaining much attention, especially in developing countries. The increase patronage of these remedies is often predicated on the assumption that they are harmless since they are prepared from natural sources. However, toxicity related to herbal medicines is becoming widely recognized. Yoyo 'Cleanser' Bitters (YB) and Fields Swedish Bitters (SB) are herbal preparations largely consumed in Nigeria because of their high publicity in the various national news media. This study evaluated their toxicity potentials following sub-chronic administration in rats. Approach: Thirty-five Wistar rats were divided into five groups of 7 rats/group. Control received normal saline while the experimental groups were treated separately with 15 and $30 \mathrm{~mL} \mathrm{~kg}^{-1}$ of YB and SB respectively. Treatment was given daily by gavage for 30 days. Body weights were measured weekly and rats were sacrificed $24 \mathrm{~h}$ after last treatment. Blood was collected by cardiac puncture for biochemical and haematological assessment. Vital organs were also excised and weighed. Results: YB and SB did not significantly affect creatinine, blood urea nitrogen, $\mathrm{Na}^{+}$ion but significantly $(\mathrm{p}<0.01)$ decreased $\mathrm{K}^{+}$ion concentration when compared with control. Both herbal preparations produced moderate increases in alanine and aspartate aminotransferase activities, with YB $\left(30 \mathrm{~mL} \mathrm{~kg}^{-1}\right)$ significantly $(\mathrm{p}<0.05)$ increasing the latter. YB and SB did not significantly alter total cholesterol, triglycerides and albumin but SB $\left(30 \mathrm{~mL} \mathrm{~kg}^{-1}\right)$ significantly $(\mathrm{p}<0.05)$ decreased total protein when compared with control. SB significantly $(\mathrm{p}<0.05)$ elevated white blood cell count while other haematological parameters, vital organs and body weights were not significantly affected by both herbal preparations. Conclusion: YB and SB possess the risk of inducing hypokalaemia. The potential to also increase markers of liver function calls for cautious use in conditions associated with liver impairment.
\end{abstract}

Key words: Yoyo Bitters, Swedish Bitters, Herbal remedies, Hepatotoxicity, Nephrotoxicity, Haematotoxicity

\section{INTRODUCTION}

Herbal medicine, in which plants (dried or in extract form) are used as therapeutic substances, is one of a number of practices encompassed by the term "Complementary and Alternative Medicine" (CAM). CAM has gained enormous popularity worldwide over the past 20 years and several studies continue to demonstrate the amazing therapeutic benefits inherent in medicinal plants (Liu et al., 2004; Ekor et al., 2006; Ekor et al., 2010, Al-Attar, 2010; Muralidhar et al., 2009.). It has been estimated that more than $80 \%$ of the developing world's population still depends on the complementary and alternative systems of medicine (Bodeker and Kronenberg, 2002). This increase in popularity or interest in alternative/herbal medicine for

Corresponding Author: Martins Ekor, Department of Chemical Sciences, Redeemer's University, km 46 Lagos/Ibadan Expressway, P.M.B. 3005, Redemption City, Ogun State, Nigeria. Tel: +234 8062353814 
the prevention and treatment of various illnesses has also brought some concerns and fears over professionalism of practitioners, quality, efficacy and safety of the 'natural' formulations available on the market (Saad et al., 2006; Mohanty et al., 2010). There are general and herb-specific concerns regarding medicinal plants and their ability to produce toxicity and adverse effects. Accidental herbal toxicity occurs not only as a result of a lack of pharmaceutical quality control in harvesting and preparation, but also because herbal remedies are believed to be harmless (Saad et al., 2006). Important additional concerns are a confusing nomenclature, lack of quality control and accurate identification of plants coupled with the fact that there are no governmental regulations on the manufacture, purity, concentration, or labeling claims of herbal remedies and dietary supplements (Sudha et al., 2009).

Over the past decade, several newsworthy episodes in developed as well as developing communities indicated adverse effects, sometimes life-threatening, allegedly arising as consequence of taking medicinal plants or traditional medicines from various ethnic groups (Elvin-Lewis, 2001; Chan, 2003; Ekor et al, 2006). In some cases, adulteration, inappropriate formulation or lack of understanding of plants, their interactions with other herbs and drugs, contaminants, adulterants; or their inherent toxicity or uses have led to adverse reactions that are sometimes life-threatening or lethal to patients (Abu-Irmaileh and Afifi, 2003; Ernst, 1998; 1999; Fugh-Berman, 2000). Plants may have complex mixtures of terpenes, alkaloids, saponins and other chemicals, increasing the risk of adverse reactions to any one of them or to the additive or synergistic effects of chemical interactions. For example, more than 100 chemicals have been identified in tea tree oil.

Today, alternative therapies have become a significant component of over-the-counter market. Consumers generally view these products as safe and effective alternatives to conventional therapies and most users include these products in their health care providers. Patients do not always comprehend the potential dangers of consuming these products. Yoyo 'Cleanser' Bitters (YB) and Fields Swedish Bitters (SB) are amongst herbal preparations that have gained much publicity through the Nigerian news media and have received wide patronage across the various geo-political zones of the country. The manufacturers and/or marketers of these herbal preparations have effectively disseminated the acclaimed effectiveness in maintaining overall health and well-being, serve as blood cleansers and effective in the management of diverse human ailments, though many of these claims are yet to have scientific backing. Yoyo Bitters is made from Acinos arvensis, Aloe, Chenopodium murale, Cinnamonum aromaticum, Citrus aurantifolia while Swedish Bitters is made from Aloe, Angelica root, Camphor, Carline thistle roots, Myrrh, Rhubarb roots, Saffron, Senna leaves, Theriac Venezian and Zedoary roots and extracted using water or alcohol as extracting medium. Assessment of the safety and efficacy of herbal medicines is an important issue both for the health professions and the consumers of these products. We believe that any plant herb or ingredients taken from plants should be adequately tested before being used as a remedy. In this study, we assessed the toxicity of Yoyo 'Cleanser' Bitters and Fields Swedish Bitters by evaluating their effects on some renal, hepatic and haematological parameters following sub-chronic administration in rats.

\section{MATERIALS AND METHODS}

Drugs and chemicals: Fields Swedish Bitters and Yoyo 'Cleanser' Bitters were obtained from Starling Nigeria Limited and Abllat Company Nigeria limited respectively. Aspartate Aminotransferase (AST), Alanine Aminotransferase (ALT), Blood Urea Nitrogen (BUN), Creatinine, Total Cholesterol (TC), Triglyceride (TG) and Albumin assay kits were obtained from Randox Laboratories (Crumlin, UK). Leishman stain and ammonium oxalate solution were obtained from BDH chemicals (England). All other chemicals and reagents used were of analytical grade.

Animals: Male albino rats of the Wistar strain weighing between 102-200 g were obtained from commercial private colony in Ibadan, Oyo-State, Nigeria. The rats were housed within the experimental animal handling facility of the Department of Pharmacology, Olabisi Onabanjo University, Nigeria, at ambient temperature and humidity with a $12 \mathrm{~h}$ light $12 \mathrm{~h}^{-1}$ dark schedule. They were fed with commercially available rat pelleted diet (Bendel Feeds, Edo State, Nigeria) and water ad libitum during period of acclimatization and throughout the period of the experiment.

Experimental design and necropsy: The animals were assigned to five experimental groups of seven rats per group. Rats in group 1 received normal saline $(30 \mathrm{~mL}$ $\mathrm{kg}^{-1}$ body weight) and served as control. Rats in groups 2 and 3 received 15 and $30 \mathrm{~mL} \mathrm{~kg}^{-1}$ body weight of YB respectively while rats in groups 4 and 5 were treated with 15 and $30 \mathrm{~mL} \mathrm{~kg}^{-1}$ body weight of $\mathrm{SB}$ respectively. Administration was through the oral route and treatment was given for thirty days. Body weights of both control and test rats were measured weekly during treatment periods and later sacrificed by cervical dislocation $24 \mathrm{~h}$ after the last treatment. Blood sample 
was collected by cardiac puncture into lithium heparin bottles and centrifuged at $4200 \mathrm{rpm}$ at room temperature for $5 \mathrm{~min}$ to separate plasma for determination of biochemical parameters. Blood for haematological analysis was collected into EDTA bottles. The liver, kidneys, lungs, heart and spleen were removed, cleared of adhering tissues and weighed. The weights were recorded in grams and expressed as $\mathrm{g} \mathrm{kg}^{-1}$ body weight.

Assessment of renal function: Renal function test was carried out by measuring BUN following principle based on the condensation of diacetyl with urea (Fearon, 1939) and plasma Creatinine (pCr) concentration according to the principle described by Jaffe et al. (1987) using commercial kits purchased from Randox Laboratories Ltd. (UK). Plasma concentrations of $\mathrm{Na}^{+}$and $\mathrm{K}^{+}$ions were determined by flame emission spectrophotometry.

Assessment of hepatic function: Liver function was assessed by measuring the activities of AST and ALT in plasma. Synthetic function of the liver was assessed by determining plasma Total Protein (TP) and albumin concentrations according to the principle based on Biuret reaction (Gornall et al., 1949) and bromocresol green reaction (Doumas et al., 1997) respectively.

Cholesterol and triglyceride assay: $\mathrm{TC}$ and $\mathrm{TG}$ concentrations were estimated using commercial kits obtained from Randox Laboratories Ltd, (Crumlin, UK).

Estimation of haematological parameters: Packed Cell Volume (PCV), Total White Blood Cell (TWBC) count, Neutrophil Count (NC), Lymphocytes Count (LC), Eosinophil (EO) and platelet count were carried out according to the methods described by Bain (1995).

Statistics: Results were expressed as mean \pm Standard Error of Mean (SEM). Differences between groups were determined by One-Way Analysis Of Variance (ANOVA) using Statistical Package for Social Sciences (SPSS) software for windows. Post hoc testing was performed for inter-group comparisons using the Least Significant Difference (LSD) (Levine, 1991) and pvalue $<0.05$ was considered significant.

\section{RESULTS}

Renal function: The effect of $\mathrm{YB}$ and $\mathrm{SB}$ on renal function is shown in Fig. 1 and 2. $\mathrm{pCr}$ and BUN concentrations were not significantly $(p>0.05)$ different in the YB and SB-treated rats when compared with control (Fig. 1). $\mathrm{Na}^{+}$ion concentrations were also not significantly $(p>0.05)$ affected by these herbal preparation (Fig. 2). YB (30 mL kg $\left.\mathrm{g}^{-1}\right)$ and SB (15 and $\left.30 \mathrm{~mL} \mathrm{~kg}^{-1}\right)$, however, significantly $(\mathrm{p}<0.01)$ decreased $\mathrm{K}^{+}$ion concentrations when compared with the salinetreated control (Fig. 2).

Hepatic function: Figure 3 shows the effect of YB and SB on plasma aminotransferases activities. While YB $\left(30 \mathrm{~mL} \mathrm{~kg}^{-1}\right) \quad$ significantly $(\mathrm{p}<0.05)$ increased AST activity, SB only produced moderate but non-significant increase in the activity of this enzyme when compared with saline control.

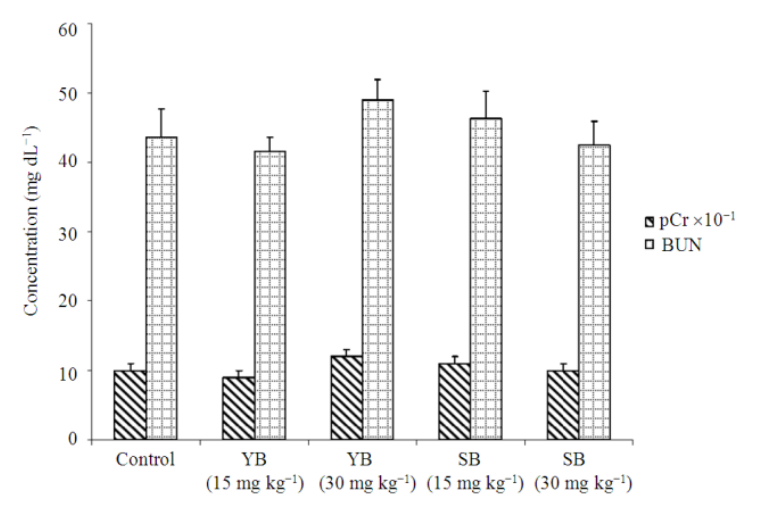

Fig. 1: Effect of sub-chronic administration of Yoyo and Swedish bitters on plasma creatinine and blood urea nitrogen Values are expressed as Mean \pm standard error of mean $\mathrm{pCr}=$ Plasma Creatinine; $\mathrm{BUN}=$ Blood Urea Nitrogen; $\mathrm{YB}=$ Yoyo Bitters; $\mathrm{SB}=$ Swedish Bitters

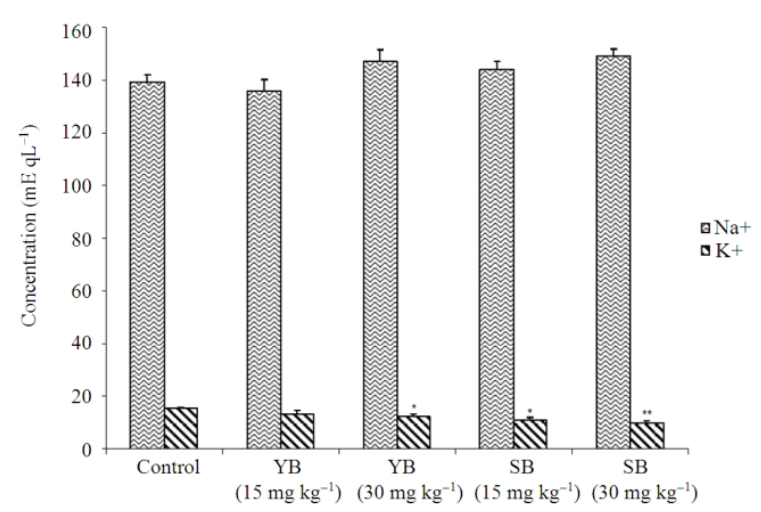

Fig. 2: Effect of sub-chronic administration of Yoyo and Swedish bitters on plasma $\mathrm{Na}_{+}$and $\mathrm{K}+$ Concentrations. Values are expressed as Mean \pm standard error of mean. ${ }^{*} p<0.01$ and ${ }^{* *} p<0.001$ when compared with control. $\mathrm{YB}=$ Yoyo Bitters; SB = Swedish Bitters 


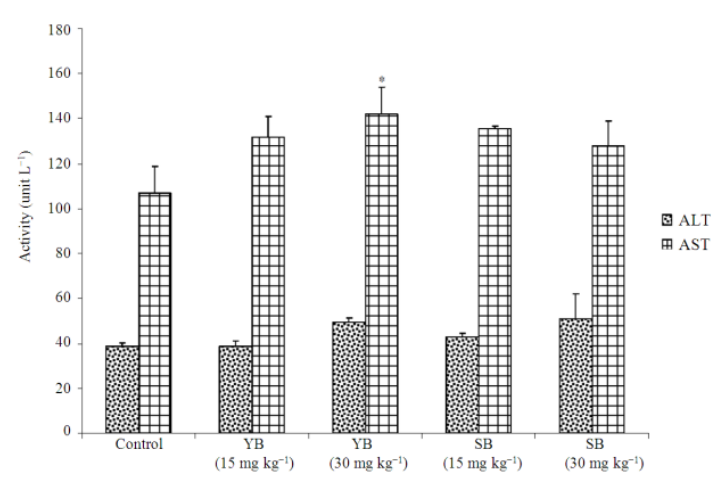

Fig. 3: Effect of sub-chronic administration of Yoyo and Swedish bitters on aspartate and alanine aminotransferases. Values are expressed as Mean \pm standard error of mean. ${ }^{*} \mathrm{p}<0.05$ when compared with control. AST $=$ Aspartate aminotransferase; $\quad \mathrm{ALT}=$ Alanine aminotransferase; $\mathrm{YB}=$ Yoyo bitters; $\mathrm{SB}=$ Swedish bitters

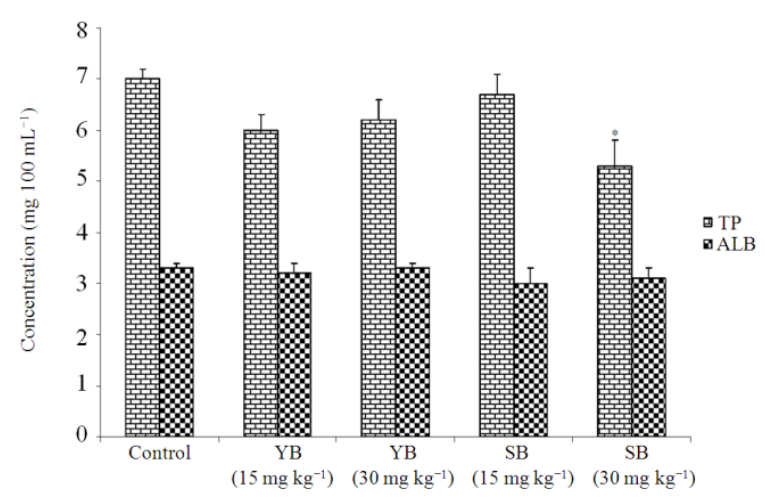

Fig. 4: Effect of sub-chronic administration of Yoyo and Swedish bitters on plasma total protein and albumin. Values are expressed as Mean \pm standard error of mean (SEM). ${ }^{*} \mathrm{p}<0.05$ when compared with control. $\mathrm{PT}=$ Total protein; $\mathrm{ALB}=$ Albumin; $\mathrm{YB}=$ Yoyo bitters; $\mathrm{SB}=$ Swedish bitters

The activity of ALT, though elevated by both herbal preparations, values were however not significantly $(p>0.05)$ different from those of the control. Similarly, albumin concentration did not change significantly $(p>0.05)$ in the YB and SB - treated rats when compared with control. SB, on the other hand, significantly $(\mathrm{p}<0.05)$ decreased TP concentration relative to control (Fig. 4).

Cholesterol and triglyceride: Plasma concentrations of TC and TG are shown in Fig. 5. Treatment with YB and SB did not significantly $(\mathrm{p}>0.05)$ change TC and TG concentrations in the rats when compared with control.

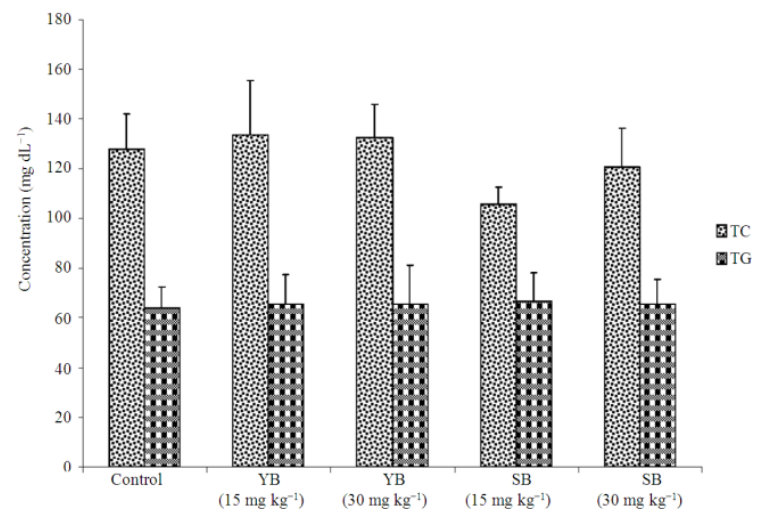

Fig. 5: Effect of sub-chronic administration of Yoyo and Swedish bitters on plasma total cholesterol and triglyceride levels. Values are expressed as Mean \pm standard error of mean. TC $=$ Total cholesterol; $\mathrm{TG}=$ Triglyceride; $\mathrm{YB}=$ Yoyo bitters; $\mathrm{SB}=$ Swedish bitters

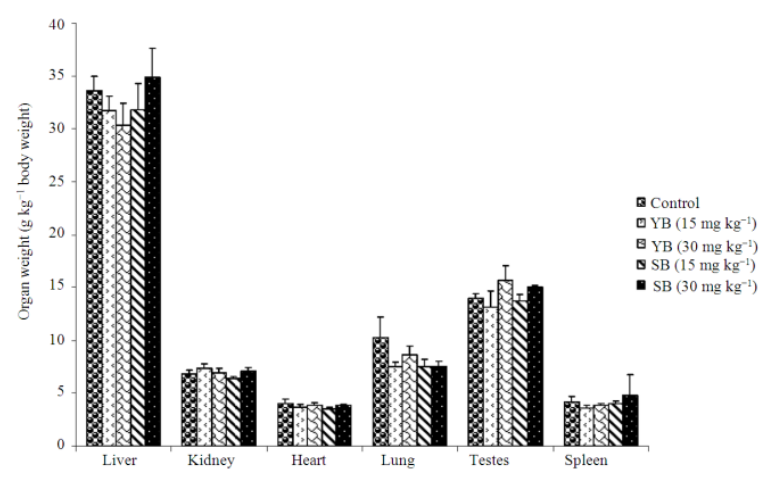

Fig. 6: Effect of sub-chronic administration of Yoyo and Swedish bitters on rats' organ weight. $\mathrm{YB}=$ Yoyo bitters; $\mathrm{SB}=$ Swedish bitters

Table1: Effect of sub-chronic administration of Yoyo and Swedish bitters on packed cell volume and white blood cell count

\begin{tabular}{lll}
\hline Treatment & PCV & WBC \\
\hline Control $\left(\right.$ Saline $\left.30 \mathrm{~mL} \mathrm{~kg}^{-1}\right)$ & $44.9 \pm 1.8$ & $12.4 \pm 1.9$ \\
YB $\left(15 \mathrm{~mL} \mathrm{~kg}^{-1}\right)$ & $44.7 \pm 1.6$ & $15.8 \pm 1.4$ \\
YB $\left(30 \mathrm{~mL} \mathrm{~kg}^{-1}\right)$ & $49.6 \pm 2.8$ & $15.9 \pm 2.5$ \\
SB $\left(15 \mathrm{~mL} \mathrm{~kg}{ }^{-1}\right)$ & $47.4 \pm 1.8$ & $21.7 \pm 1.0^{*}$ \\
SB $\left(30 \mathrm{~mL} \mathrm{~kg}{ }^{-1}\right)$ & $49.3 \pm 1.9$ & $20.2 \pm 1.7^{*}$ \\
\hline V
\end{tabular}

Values are expressed as Mean \pm Standard Error of Mean (SEM). *: $\mathrm{p}<0.01$ when compared with control. $\mathrm{PCV}=$ Packed Cell Volume; $\mathrm{WBC}=$ White Blood Cell; YB $=$ Yoyo Bitters; $\mathrm{SB}=$ Swedish Bitters

Haematological parameters: WBC count was significantly $(p<0.05)$ increased in the SB-treated rats while only mild increase was observed in the YBtreated group when compared with the saline control (Table 1). Also, YB and SB did not significantly change neutrophil, lymphocyte, eosinophil and platelet counts in rats treated with them when compared with the control group (Table 2). 
Am. J. Pharm. \& Toxicol., 5 (4): 159-166, 2010

Table 2: Effect of sub-chronic administration of Yoyo and Swedish bitters on neutrophil, lymphocyte, platelet, eosinophil levels

\begin{tabular}{|c|c|c|c|c|}
\hline Treatment & NT & LP & PT & EO \\
\hline Control (Saline $10 \mathrm{~m} \mathrm{~L} \mathrm{~kg}^{-1}$ ) & $19.1 \pm 3.0$ & $80.0 \pm 3.1$ & $244.3 \pm 47.4$ & 02 \\
\hline YB $\left(15 \mathrm{~m} \mathrm{~L} \mathrm{~kg}^{-1}\right)$ & $22.3 \pm 7.1$ & $77.0 \pm 7.0$ & $276.7 \pm 76.3$ & 02 \\
\hline YB $\left(30 \mathrm{~m} \mathrm{~L} \mathrm{~kg}^{-1}\right)$ & $20.2 \pm 6.6$ & $79.8 \pm 6.5$ & $254.0 \pm 55.3$ & - \\
\hline $\mathrm{SB}\left(15 \mathrm{~m} \mathrm{~L} \mathrm{~kg}^{-1}\right)$ & $10.4 \pm 2.3$ & $89.6 \pm 2.3$ & $368.0 \pm 57.1$ & - \\
\hline $\mathrm{SB}\left(15 \mathrm{~m} \mathrm{~L} \mathrm{~kg}^{-1}\right)$ & $21.0 \pm 5.8$ & $79.0 \pm 5.84$ & $405.0 \pm 17.1$ & - \\
\hline
\end{tabular}

Values are expressed as Mean \pm Standard Error of Mean $(\mathrm{SEM}) . \mathrm{NT}=$ Neutrophil; LP $=$ Lymphocyte; PT $=$ Platelet; EO $=$ Eosinophil; YB $=$ Yoyo Bitters; $\mathrm{SB}=$ Swedish Bitters

Table 3: Effect of sub-chronic administration of Yoyo and Swedish bitters on rats' body weight

\begin{tabular}{|c|c|c|c|c|c|}
\hline \multirow[b]{2}{*}{ Treatment } & \multicolumn{5}{|c|}{ Body weight (g) } \\
\hline & WK1 & WK2 & WK3 & WK4 & WK5 \\
\hline Control & $107.4 \pm 3.1$ & $107.7 \pm 3.1$ & $115.0 \pm 4.6$ & $114.7 \pm 6.2$ & $131.7 \pm 8.1$ \\
\hline (Saline, $30 \mathrm{~mL} \mathrm{~kg}^{-1}$ ) & - & $(-0.3)^{\mathrm{a}}$ & $(-7.1)^{\mathrm{a}}$ & $(-7.0) \mathrm{a}$ & $(-22.6)^{\mathrm{a}}$ \\
\hline YB $\left(15 \mathrm{~mL} \mathrm{~kg}^{-1}\right)$ & $\begin{array}{l}110.2 \pm 8.7 \\
- \\
(-2.6)^{b}\end{array}$ & $\begin{array}{l}116.3 \pm 9.9 \\
(-5.5)^{\mathrm{a}} \\
(-8.0)^{\mathrm{b}}\end{array}$ & $\begin{array}{l}117.7 \pm 11.3 \\
(-6.8)^{\mathrm{a}} \\
(-2.3)^{\mathrm{b}}\end{array}$ & $\begin{array}{l}126.0 \pm 13.2 \\
(-14.3)^{\mathrm{a}} \\
(-9.9) \mathrm{b}\end{array}$ & $\begin{array}{l}141.7 \pm 10.4 \\
(-28.6)^{\mathrm{a}} \\
(-7.6)^{\mathrm{b}}\end{array}$ \\
\hline YB $\left(15 \mathrm{~mL} \mathrm{~kg}^{-1}\right)$ & $\begin{array}{l}103.4 \pm 7.3 \\
- \\
(3.7)^{b}\end{array}$ & $\begin{array}{l}107.6 \pm 9.5 \\
(-4.1)^{\mathrm{a}} \\
(0.09) \mathrm{b}\end{array}$ & $\begin{array}{l}129.2 \pm 6.1 \\
(-25.0)^{\mathrm{a}} \\
(-12.3)^{\mathrm{b}}\end{array}$ & $\begin{array}{l}136.0 \pm 7.3 \\
(-31.5)^{\mathrm{a}} \\
(-18.6)^{\mathrm{b}}\end{array}$ & $\begin{array}{l}138.4 \pm 7.0 \\
(-33.5)^{\mathrm{a}} \\
(-5.1) \mathrm{b}\end{array}$ \\
\hline $\mathrm{SB}\left(15 \mathrm{~mL} \mathrm{~kg}^{-1}\right)$ & $\begin{array}{l}105.2 \pm 7.3 \\
- \\
(2.0)^{b}\end{array}$ & $\begin{array}{l}118.0 \pm 6.2 \\
(-12.2)^{\mathrm{a}} \\
(-9.6) \mathrm{b}\end{array}$ & $\begin{array}{l}131.6 \pm 7.3 \\
(-25.1)^{\mathrm{a}} \\
(-14.4)^{\mathrm{b}}\end{array}$ & $\begin{array}{l}139.4 \pm 10.8 \\
(-32.5)^{\mathrm{a}} \\
(-21.5)^{\mathrm{b}}\end{array}$ & $\begin{array}{l}147.6 \pm 13.6 \\
(-40.3)^{\mathrm{a}} \\
(-12.1)^{\mathrm{b}}\end{array}$ \\
\hline YB $\left(15 \mathrm{~mL} \mathrm{~kg}^{-1}\right)$ & $\begin{array}{l}114.0 \pm 6.4 \\
- \\
(-6.1)^{b}\end{array}$ & $\begin{array}{l}125.5 \pm 7.4 \\
(-10.1)^{\mathrm{a}} \\
(-16.5)^{\mathrm{b}}\end{array}$ & $\begin{array}{l}126.5 \pm 9.5 \\
(-11.0)^{\mathrm{a}} \\
(-10.0)^{\mathrm{b}}\end{array}$ & $\begin{array}{l}137.5 \pm 6.0 \\
(-20.6)^{\mathrm{a}} \\
(-19.9)^{\mathrm{b}}\end{array}$ & $\begin{array}{l}138.0 \pm 3.5 \\
(-21.1)^{\mathrm{a}} \\
(-4.8)^{\mathrm{b}}\end{array}$ \\
\hline
\end{tabular}

Values are expressed as Mean \pm standard error of mean (SEM). ${ }^{\text {a }}$ : percentage change relative to WK1; ${ }^{\text {b }}$ : percentage change relative to control; $(=$ $\%$ increase; $(+)=\%$ decrease. $\mathrm{WK}=$ week; $\mathrm{YB}=$ Yoyo Bitters; $\mathrm{SB}=$ Swedish Bitters

Organ and Body weights: Rats' body weights and organ weights relative to body weights in all treatment groups are presented in Table 3 and Fig. 6 respectively. YB at 15 and $30 \mathrm{~mL} \mathrm{~kg}{ }^{-1}$ doses produced 28.6 and $33.5 \%$ increase in body weight respectively at week 5 compared to $22.6 \%$ increase in body weight recorded for control rats. SB, on the other hand, produced 40.3 and $21.1 \%$ increases at the same doses respectively at week 5 . The percentage change in rats' body weights produced by these herbal preparations was not significant when compared with control. Similarly, YB and SB did not produce any significant $(\mathrm{p}>0.05)$ change in organ weights relative to body weight at the end of week 5 when compared with control (Fig. 6).

\section{DISCUSSION}

There has been suggestions and recommendations on the need to implement increase public awareness and education programs for healthcare professionals about the potential dangers of herbal preparations, in addition to the regulation of their proliferation by the various Food and Drug Administrations (Chitturi and Farrell, 2000; Pak et al., 2004; Joshua et al., 2010). In spite of the high consumption of herbal products or remedies among the Nigerian population and in most developing countries, much attention has not been paid to the evaluation of the safety of these preparations. This present study evaluated the safety of Yoyo 'Cleanser' Bitters, a locally produced herbal medicine and Fields Swedish Bitters (imported and marketed in Nigeria) by assessing their effects on markers of renal, hepatic and haematopoietic functions following sub-chronic administration in rats. Results from this study show that daily administration (in single dose) of both YB and SB for thirty days did not affect renal functions. $\mathrm{pCr}$ and BUN concentrations (indicators of glomerular function) in the rats that received these herbal preparations were not significantly different from those of the salinetreated control rats. Although these herbal remedies produced mild but insignificant increase in $\mathrm{Na}^{+}$ion concentration, they however appear to possess a strong predisposition to inducing hypokalaemia. While YB produced this effect at the higher dose $\left(30 \mathrm{~mL} \mathrm{~kg}^{-1}\right), \mathrm{SB}$ on the other hand, significantly decreased $\mathrm{K}^{+}$ion concentration at both doses. It has been observed that low level of plasma potassium could be as a result of elevated levels of aldosterone, renal tubular acidosis and low body magnesium level. The pattern of electrolyte disturbance (mild elevation of $\mathrm{Na}^{+}$with $\mathrm{K}^{+}$ loss) produced by these herbal remedies may be related to the activation of the renin-angiotensin-aldosterone 
system as this has been observed with stimulation of the system. When hypokalemia reflects true potassium depletion, the body activates several mechanisms especially the kidney to conserve potassium. Short periods of mild potassium depletion have been shown to be capable of inducing serious cardiac, renal and neurologic dysfunction (Reungjui et al., 2008). Prolonged potassium depletion of even modest proportion can provoke or exacerbate kidney injury or hypertension (Khosla and Hogan, 2006). Also, reduced plasma potassium has been shown to correlate directly with higher blood pressure in both normotensive and hypertensive individuals (Whelton et al., 1997). The ability of YB and SB, therefore, to induce hypokalaemia following prolonged administration calls for cautious use especially in individuals with underlying cardiac or renal conditions.

Furthermore, treatment with $\mathrm{YB}$ and $\mathrm{SB}$ raised plasma aminotransferases (AST and ALT) activity. Although the effect of SB on the activity of these enzymes was not significant, YB on the other hand, significantly raised AST activity. Since AST is not specific for liver function, the significant increase in its activity in the YB-treated rats may reflect hepatic and/or extra-hepatic toxicity. The mild to moderate increase in plasma aminotransferases observed in this study was not associated with a decline in the metabolic function of the liver. This was reflected in the plasma concentrations of TC and TG which did not change significantly in the test groups when compared with control. However, the significant decrease in plasma TP by SB may reflect a decrease in the synthetic function of the liver in these rats. It thus appears that these herbal preparations may predispose to impairment of liver function on prolonged administration, but it is not clear if this could be significant enough to precipitate overt liver failure. Most reports of toxic effects due to the use of herbal medicines and dietary supplements are associated with hepatotoxicity although reports of other toxic effects including kidney, nervous system, blood, cardiovascular and dermatologic effects, mutagenicity and carcinogenicity have also been reported (Saad et al., 2006; See et al., 2010). Hepatic impairment resulting from the use of conventional drugs is widely acknowledged, but there is less awareness of the potential hepatic toxicity of herbal preparations and other botanicals, many of which are believed to be harmless and are commonly used for self-medication without supervision (Chitturi and Farrell, 2000; Pak et al., 2004; Mohanty et al., 2010). The reported toxicity of herbal formulations has been suggested to be the result of several factors, including the contamination with pesticides, microbes, heavy metals, toxins or adulteration with orthodox drugs (ElNahhal, 2004; Fugh-Berman, 2000; Wu et al., 1996; See et al., 2010; Sudha et al., 2009). On the basis of various case reports, the liver injury from herbal remedies has ranged from mild elevations of liver enzymes to fulminated liver failure requiring liver transplantation (Woolf, 2003). For example, venoocclusive disease was caused by pyrrolizidine alkaloids, such as Senecio species, Heliotropium species and Comfrey (Symphytum officinale). Chapparal (Larrea divericata) leaf ingestion could lead to the development of either fulminant hepatic failure or cirrhosis. Kava (Piper methysticum) has been identified as causing an acute hepatitis. Many traditional Chinese herbal preparations have also been described to cause hepatotoxicity but rarely liver failure (Woolf, 2003).

Our results further reveal that treatment with YB and SB did not alter PCV and values in all the treatment groups were similar with those of the control. While YB did not produce any significant change in WBC count, $\mathrm{SB}$ on the other hand, significantly increased this haematological parameter. WBCs are known to play important role in the immune system. They fight infections in a process known as phagocytosis, where they surround the foreign organisms and destroy it. WBCs also help in the production, transportation and distribution of antibodies in order to build the body's immune system. The SB-induced increase in WBC observed in this study could reflect an enhancement or boost of the rats' immune system. We would also like to quickly point out that elevated or too much WBCs is not always synonymous with improved immunity. Sometimes, it could indicate an underlying problem and that is the reason high WBC would always require further medical evaluation as it could indicate infection, trauma, inflammation, tissue damage, allergy amongst others. It has also been associated with the use of certain medications like corticosteroids, antibiotics, antiepileptic drugs, (Tefferi et al., 2005). The observed increase in WBC in this study could be attributed to any of the aforementioned. Furthermore, treatment with YB and SB did not significantly affect other haematological parameters (neutrophil, lymphocytes, eosinophil and platelet). Similarly, organ weights as well as the overall body weights of rats were not significantly affected by these herbal medicines in this study.

\section{CONCLUSION}

In conclusion, $\mathrm{YB}$ and $\mathrm{SB}$ possess the risk of inducing hypokalaemia. Because of the observed tendency of these herbal remedies to also raise plasma marker enzymes for liver function, it is advisable they 
are used with caution in conditions associated with liver impairment. In view of the potential harmful effects of various herbal preparations on the liver and other vital organs, it becomes necessary to carry out detailed chronic toxicity evaluation of the individual and the combined constituents that have been formulated into preparing $\mathrm{YB}$ and $\mathrm{SB}$.

\section{ACKNOWLEDGEMENTS}

Authors gratefully acknowledge the contributions of Prof. E.O. Ogunyemi (Head, Department of Chemical Pathology, Olabisi Onabanjo University Teaching Hospital, Ogun State, Nigeria) and Dr. (Mrs) O.E. Ekor for their contributions.

\section{REFERENCES}

Abu-Irmaileh, B.E. and F.U. Afifi 2003. Herbal medicine in Jordan with special emphasis on commonly used herbs. J. Ethnopharmacol, 89: 193197. DOI: 10.1016/S0378-8741(03)00283-6

Al-Attar, A.M., 2010. Antilithiatic influence of spirulina on ethylene glycol-induced nephrolithiasis in male rats. Am. J. Biochem. Biotechnol., 6: 25-31. DOI:10.3844/ajbbsp.2010.25.31

Bodeker, G. and F. Kronenberg, 2002. A public health agenda for traditional, complementary and alternative medicine. Am. J. Publ. Health, 92: 1582-1591.

Chan, K., 2003. Some aspects of toxic contaminants in herbal medicines. Chemosphere, 52: 1361-1371. DOI:10.1016/S0045-6535(03)00471-5 PMID: 12867165

Chitturi, S. and G.C. Farrell, 2000. Herbal hepatotoxicity: an expanding but poorly defined problem. J. Gastroenterol Hepatol, 15: 1093-1099. DOI: $10.1046 /$ j.1440-1746.2000.02349.x PMID: 11106086

Bain, B., 1995. Basic Haematological Techniques. In: Practical Haematology, Dacie, J.V. and S.M. Lewis, (Eds.). Churchill Livingstone, USA., ISBN10: 0443049319, pp: 49-82.

Doumas, B.T., W.A. Watson and H.G. Biggs, 1997. Albumin standards and the measurement of serum albumin with bromcresol green. Clinical Chemistry, 258: 21-30. DOI: 10.1016/S00098981(96)06447-9
Ekor, M., A.O. Odewabi, A.G. Bakre, K.S. Oritogun and T.E. Ajayi et al., 2010. Comparative evaluation of the protective effect of the ethanolic and methanolic leaf extracts of Sida acuta against hyperglycaemia and alterations of biochemical and haematological indices in alloxan diabetic rats. J. Pharmacol. Toxicol., 5: 1-12. DOI: 10.3923/jpt.2010.1.12

Ekor, M, G.K.A. Adepoju and E.A. Ayodeji, 2006. Protective effect of the methanolic leaf extract of Persea americana (Avocado) against paracetamolinduced acute hepatotoxicity in rats. Int. J. Pharmacol., 2: 416-420. DOI: 10.3923/ijp.2006.416.420

El-Nahhal, Y., 2004. Contamination and safety status of plant and food in Arab countries. J. Appl. Sci., 4: 411-417. DOI: $10.3923 /$ jas.2004.411.417

Elvin-Lewis, M., 2001. Should we be concerned about herbal remedies? J. Ethnopharmacol, 75: 141-164. DOI: 10.1016/S0378-8741(00)00394-9

Ernst, E., 1998. Harmless herbs? A review of the recent literature. Am. J. Med., 104: 170-178. PMID: 9528737

Ernst, E., 1999. Herbal medications for common ailments in the elderly. Drugs Aging, 15: 423-428. PMID: 10641953

Fearon, W.R. 1939. The carbamido diacetyl reaction: a test for citrulline. Biochem, J., 33: 902-907. PMID: 16746990

Fugh-Berman, A., 2000. Herb-drug interactions. Annieappleseedproject.

Gornall, A.G., C.J. Bardawill and M.M. David, 1949. Determination of serum proteins by means of the biuret reaction. J. Biol. Chem., 177: 751-766. PMID: 18110453

Jaffe, N., R. Keifer, R. Robertson, A. Cangir and A. Wang, 1987. Renal toxicity with cumulative doses of cis-diamminedichloroplatinum-II in pediatric patients with osteosarcoma Effect on creatinine clearance and methotrexate excretion. Cancer, 59: 1577-1581. DOI: 10.1002/10970142(19870501)59:9<1577::AIDCNCR2820590908>3.0.CO;2-P

Joshua, A.J., K.S. Goundar, N. Sameera, G.P. Kumar and B. Murali et al., 2010. Safety assessment of herbal formulations, Rumbion ${ }^{\mathrm{TM}}$ and Tyrel $^{\mathrm{TM}}$ in albino wistar rats. Am. J. Pharmacol. Toxicol., 5: 42-47. DOI:10.3844/ajptsp.2010.42.47 
Khosla, N. and D. Hogan, 2006. Mineralocorticoid hypertension and hypokalemia. Semin Nephrol, 26: 434-440. DOI: 10.1016/j.semnephrol.2006.10.004

Levine, G., 1991. A guide to SPSS for analysis of variance. 1st Edn., Psychology Press, USA., ISBN10: 0805809414, pp: 176.

Liu, F., Y. Liu, Y. Meng, M. Yang and K. He, 2004. Structure of polysaccharide from Polygonatum cyrtonema Hua and the antiherpetic activity of its hydrolyzed fragments. Antiviral Res., 63: 183-189. PMID: 15451186

Mohanty, N.K., R.L. Nayak and Pralhad S. Patki, 2010. Safety and efficacy of an ayurvedic formulation cystone in management of ureteric calculi: a prospective randomized placebo controlled study. Am. J. Pharmacol. Toxicol., 5: 58-64. DOI: 10.3844/ajptsp.2010.58.64

Pak, E., K.T. Esrason and V.H. Wu, 2004. Hepatotoxicity of herbal remedies: An emerging dilemma. Prog. Transplant, 14: 91-96. PMID: 15264453

Reungjui, S., C.A. Roncal, W. Sato, O.Y. Glushakova and B.P. Croker et al., 2008. Hypokalemic nephropathy is associated with impaired angiogenesis. J. Am. Soc. Nephrol, 19: 125-134. DOI: 10.1681/ASN.2007030261

Saad, B., H. Azaizeh, G. Abu-Hijleh and O. Said, 2006. Safety of traditional arab herbal medicine. Evidence-Based Complementary Altern. Med., 3: 433-439. DOI: 10.1093/ecam/nel058

Muralidhar, T.S., A. Balaji, C. Bandopadhyay and S.L. Shantha, 2009. Cytoprotective effect of ulgen, a polyherbal formulation against physical and chemical factor induced gastric ulcers in wister albino rats. Am. J. Pharmacol. Toxicol., 4: 80-84. DOI: 10.3844/ajptsp.2009.80.84
See, A.S., A.B. Salleh, F.A. Bakar, N.A. Yusof and A.S. Abdulamir et al., 2010. Risk and health effect of boric acid. Am. J. Applied Sci., 7: 620-627. DOI:10.3844/ajassp.2010.620.627

Sudha, A., V.S. Murty and T.S. Chandra, 2009. Standardization of metal-based herbal medicines. Am. J. Infect. Dis., 5: 193-199. DOI:10.3844/ajidsp.2009.193.199

Tefferi, A., C.A. Hanson and D.J. Inwards 2005. How to Interpret and pursue an abnormal complete blood cell count in adults. Mayo Clin. Proc., 80: 923-936. DOI: 10.4065/80.7.923

Whelton, P.K., He, J., J.A. Cutler, F.L. Brancati and L.J. Appel et al., 1997. Effects of Oral Potassium on Blood Pressure: Meta-analysis of Randomized Controlled Clinical Trials. JAMA., 277: 1624-1632. PMID: 9168293

Woolf, A.D., 2003. Herbal remedies and children: Do they work? Are they harmful? Pediatrics, 112: 240-246. PMID: 12837916

Wu, M.S., J.J. Hong, J.L. Lin, C.W. Yang and H.C. Chien, 1996. Multiple tubular dysfunction induced by mixed Chinese herbal medicines containing cadmium. Nephrol. Dial Transplant, 11: 867-870. PMID: 8671913 